\title{
Chapter 8 \\ Environmentally Responsible Happy \\ Nation Index: A Proposed National \\ Success Indicator
}

\begin{abstract}
The average happy life years HLY (of a country) is the product of the average happiness (or life satisfaction) index and the life expectancy index. Adjusting HLY to get rid of the misleading parts with negative happiness to obtain the adjusted or net HLY; deducting again the per-capita environmental costs imposed on others, we obtain the 'environmentally responsible happy nation index' as an internationally acceptable national success indicator that accounts positively for long and happy lives but negatively at the external costs of environmental disruption imposed on others and in the future. Hopefully, this 'environmentally responsible happy nation index' will lead to some re-orientation of both the market and national governments towards something more fundamentally valuable.
\end{abstract}

\subsection{Introduction}

For many decades, some measures of national income (GDP, GNP and its per capita values) have been used as a comprehensive achievement or success indicator of a nation, at least in the economic sphere. The inadequacy of such income measures prompts the development of improvements or alternative measures, including the proposals in the 1970's for taking account of leisure time and pollution, a 'genuine progress indicator' (Halstead 1998; Hamilton 1998), a 'measure of domestic progress' (Jackson 2004), and the launching by the United Nations of the Human Development Report in 1990 (which provides the Human Development Index, the Gender-related Development Index, the Gender Empowerment Measure, and the Human Poverty Index). The Human Development Index combines indices of life expectancy, education, and PPP-adjusted GDP per capita. While such indices are certainly relevant, they are still inadequate. Thus, it is 'perfectly possible ... to be well-educated, free of illness and rich, but miserable and lonely' (Marks et al. 2006, p. 6).

As happiness is the only intrinsic value, ultimately speaking (Chap. 5), and as economic growth no longer increase happiness significantly after a rather low level of survival and comfort (Chap. 7), it is natural that we should look for a largely happiness-based index. Thus, the focus on happiness and its relationships with 
economic and other variables by economists since the commencement of this century (e.g. Frey and Stutzer 2002a; Layard 2005; van Praag \& Ferrer-i-Carbonell 2004; Di Tella and MacCulloch 2006) is to be welcome. Sociologists and other researchers have also devised various measures of quality of life (QOL) indicators (see Hagerty et al. 2001 for a review and a set of criteria for evaluating the indexes, and Ridzi et al. 2020 for some recent discussion). However, as emphasized by Hajiran (2006, pp. 33-4), "Improving QOL is just “a means" and not "an end" in itself. The ultimate goal of improving QOL is to maintain and enhance the scope, depth and intensity of human well-being or "happiness"". Thus, good QOL indicators should reflect this ultimate goal. More subjective indices have also been proposed, from Andrews and Withey (1976) and Campbell et al. (1976) to Diener (2000), Cummins et al. (2003), and Kahneman et al. (2004), Tanaka and Tokimatsu (2020).

For an individual, happiness or welfare ${ }^{1}$ is probably the most important ultimate objective. However, at the national and global level and for the welfare of the future, we have to consider two related factors, the possible costs imposed on others and the sustainability of the situation. The most important variable here is the environmental disruption imposed on our life support systems.

We do not really want just a single index. For different purposes, different indices may be relevant (Cf. Ruggeri et al. 2020). For example, even just for purely economic production, even after we know the GDP figure, we may still want to know the figure for say total output of cars. On the other hand, some indices could certainly be improved. For example, the gross material production index used by the former centrally planned economies that involves double counting over different stages of production (e.g. wheat, flour, and bread all counted at their full values, not just values added) but that excludes services can be seen to be inferior to the modern concept of national income or product. The former index had thus been discarded.

It is the purpose of this chapter to propose some improvements over certain measures and to advance a measure of national success indicator that takes into account the ultimate objective of life and the external costs imposed on others and on the future. In particular, this chapter argues that.

- Existing method of calculating the measure of happy life years should be revised to give a more accurate figure (Sect. 8.3).

- A revised index called the environmentally responsible happy nation index (ERHNI) is proposed as an internationally more acceptable national success indicator (Sect. 8.4) and calculated for the various countries with the relevant data (Sect. 8.5).

- $\mathrm{ERHNI}=$ revised HLY - per capita external costs.

\footnotetext{
${ }^{1}$ These two terms are used interchangeably here. In everyday usage, happiness probably refers to current situation while welfare refers to the long term. For any given time period, the two are the same. If I am very happy over a certain period, my welfare over that period must be high. On the other hand, 'utility' which represents 'preference' may differ from happiness due to ignorance (including imperfect foresight), a concern for the welfare of others, and imperfect rationality; see Chap. 2.
} 


\subsection{Revising the Measurement of Happy Life Years}

Since happiness (or other similar measures like life satisfaction) is measured for a given period (like a week or a year) but an individual may live a short or a long live, the happiness index itself does not give the total amount of happiness enjoyed over the whole lifespan. The concept of happy life years (Veenhoven ) is conceived to overcome this problem. Conceptually, HLY is just the product of the average happiness index over the lifespan and the length of the lifespan (of life expectancy). For any given average happiness level (if positive), everyone would like to live a longer than a shorter life. Thus, HLY is an important extension of the measurement of happiness. However, an important revision in the actual measurement of HLY is needed.

As measured by Veenhoven (2005), happy-life-years = happiness (index in the range of $0-1$ ) times life-expectancy at birth (in years). The happiness index is converted from the normal index in the range $0-100$ or $0-10$ into $0-1$, e.g. an index of 50 (out of 100) is converted into 0.5 . This measure has the following problem. It is well known that, for a scale of $0-10$, the figure of 5 typically corresponds to the level of neutrality in net happiness. Since the level of overall net happiness can be either positive or negative (an individual can be happy or unhappy), and since the figure of $50 \%$ is typically used as the bare passing grade in schools, most people also habitually use the figure of 5 out of 10 or 50 out of 100 to represent the level of zero net happiness as is also the case for the curve in Fig. 1.1. (Some surveys explicitly locate the neutrality point at 5.) The average happiness indices of most nations in the world fall within the range of 4 to 8 (out of 10).

Consider the following two situations:

- A. An average happiness index of 4 (out of 10) with a lifespan of 100, giving a HLY index of 40 (with the happiness index normalized to the range $0-1$ as in Veenhoven's measure);

- B. An average happiness index of 6.5 (out of 10) with a lifespan of 60, giving a HLY index of 39.

Which situation or life experience would you rather have? Since an index of 5 means neutrality (neither happy nor unhappy), the index of 4 really mean unhappiness, with negative net happiness, or unhappiness more than happiness. For such a life, it is better to have a shorter than a longer life, as a longer life really mean longer suffering. Thus, most people will definitely choose B over A. However, existing measure of HLY rank A higher than B. This is very misleading.

This difficulty can be easily overcome. We should count only the value over neutrality as being valuable. In the above example, the adjusted HLY for the two situations are calculated as:

A. (4-5) times 0.1 (conversion to the scale of $0-1)$ times $100=-10$ (minus ten). B. $(6.5-5)$ times 0.1 times $60=9$.

The superiority of B over A can then be reflected by the positive index of 9 for B over the negative figure of minus 10 for $\mathrm{A}$. 
Without the above adjustment, the problem still remains even if no happiness index below the neutrality level of 5 is involved. Consider:

- C. An average happiness index of 5.1 with a lifespan of 100 , giving an unadjusted HLY index of 51.

- D. An average happiness index of 8 with a lifespan of 60 , giving an unadjusted HLY index of 48.

Again, most people would rather have a very happy life of 60 years rather than a barely worth living life of 100 years. The adjusted HLY gives:

- $\mathrm{C}:(5.1-5)$ times 0.1 times $100=1$.

- D: $(8-5)$ times 0.1 times $60=18$.

This shows a clear superiority of D over $\mathrm{C}$ as consistent with the preferences of most people, as well as with rationality.

If the above adjustment is done, is the adjusted HLY an appropriate national success indicator?

\subsection{Towards an International Acceptable National Success Indicator}

For an individual, ignoring the effects on others, the adjusted HLY seems an appropriate indicator. However, for a whole nation, if say America is able to achieve a very high adjusted HLY, but only by imposing very high environmental costs, making people in other countries and in the future suffer enormously, this is not a good outcome. (On the importance of the natural environment for happiness, see Chaps. 5 and 6, World Happiness Report 2020.) Thus, to provide an appropriate national success indicator, it seems natural to allow for the adjusted HLY positively, and the (per-capita) net external costs imposed on others negatively. In principle, the net external costs may account for the balance of various external costs and benefits. Due to the overwhelming importance of environmental protection, we may concentrate on the costs of environmental disruption. We then have the environmentally responsible happy nation index (ERHNI) as our proposed national success indicator,

ERHNI = Adjusted HLY — per capita external costs

where ERHNI = Environmentally Responsible Happy Nation Index. ${ }^{2}$

\footnotetext{
${ }^{2}$ A possible issue is whether the equality in happiness should be taken into account. In my view, inequality in income is undesirable both because of the diminishing marginal utility of income and because of the indirect undesirable effects of inequality in reducing happiness through for example reducing social cohesion. Since happiness is already the ultimate objective, we can neither have diminishing marginal happiness of happiness nor further indirect effects, except in an intertemporal framework where the happiness in the future has not yet been accounted for. (Correctly accounting for this intertemporal effect, an objective function that is not linear in individual happiness can be shown to violate some compelling axiom, i.e. treating a perceptible increment of happiness as less
} 
The index for per capita external costs measures the aggregate costs imposed on the global community by the nation concerned in per capita terms. Note that the "per capita' here is in the sense of per person within the home nation. Thus, if a nation of 1 billion persons imposes a total environmental costs on the rest of the world (including the future) equivalent to 6 billion Adjusted HLY, its per capita external cost is not 0.1 ( 6 billion/60 billion) but rather 6 ( 6 billion/1 billion). Thus, ERHNI measures the amount of happy life years a nation achieves for an average person less the per capita costs imposed externally on the global community. A nation that achieves a high HLY and a low PCEC (and hence a high ERHNI) not only entails high happy life years for its own residents but also imposes low (per capita) costs externally (on others). Since the main form of external costs is probably environmental disruption, the index is called 'environmentally responsible happy nation index' (ERHNI). If ERHNI is accepted as a measure of national success, governments and people in different nations around the world will not only each strive to achieve a high level of HLY but will also strive to lower the costs imposed on others. This will enhance the ability of each nation to achieve a high HLY index and the ability of the world to sustain a high HLY more permanently.

If we sum the two terms (on the right hand side of the above equation) to get ERHNI, the two terms have to be in comparable units. Since the relevant external costs are on the whole world including the effects in the future, we cannot expect to have a very accurate estimate. However, starting with some imperfect estimates (or even just guestimates) may have the advantage of leading to more accurate estimates. It is better to be roughly right on important things than to be perfectly accurate on things that are irrelevant. Since environmental disruption is clearly a very important issue that may even threaten our survival, it is imperative that we have some national success indicator that gives sufficient recognition of the negative environmental costs. The concept of green GDP takes some account of this. However, recent happiness studies (see summaries in e.g. Frey and Stutzer 2002a; Layard 2005; Kahneman and Krueger 2006; Ahuvia 2008; Asadullah et al. 2018; Cheng et al. 2018; Luo et al. 2018; Sherman et al. 2020) show that, at the social level (where individual relative competition cancels out) incomes above a relatively low level does not increase happiness (at least not to any significant extent). Thus, income is inferior to happiness as the ultimate national success indicator. Secondly, depending on the particular method of adjustment (from the traditional GDP), the measure of green GDP may mainly emphasize the environmental effects on the country concerned, while the concept of ERHNI emphasize the costs imposed on others and the future. Also, though we propose to start with environmental costs, the concept of external costs in ERHNI need not be confined to environmental costs. Once we shift from income to happiness, the environmental costs internal to the country concerned is already largely reflected in the measure of HLY of that country, though some effects on the

important than a less than a perceptible one; see $\mathrm{Ng} \mathrm{1975,1984.)} \mathrm{Moreover,} \mathrm{the} \mathrm{argument} \mathrm{for} \mathrm{the}$ utilitarian social welfare function ( $\mathrm{Ng} 2000$, Chap. 5; also Chap. 5) supports not taking into account inequality in the ultimate objective. Also, Ott (2005) shows that higher average happiness tends to go with higher equality in happiness. 
future may still not be fully captured. Thus, for the measure of ERHNI, we focus on the environmental costs external to that nation and imposed on the world.

What should be included under external costs could be further discussed. However, we may start with the global environmental costs imposed by a nation. Before a more comprehensive measure of PCEC or its main component per capita global environmental costs has been calculated, $\mathrm{Ng}$ (2008) uses the figures for $\mathrm{CO} 2$ emissions calculated by the United Nations' Department of Economic and Social Affairs as the proxy. This is based on the reasoning that the most important global environmental cost is probably that of global warming which is threatening the sustainability of the whole life support system of the whole world. $\mathrm{CO} 2$ is the principal greenhouse gas. Thus, using $\mathrm{CO} 2$ emissions may be a better proxy for external costs than the full ecological footprint which includes both external and non-external items. In any case, our calculation is mainly illustrative. When a more appropriate figure for the external cost index is available, it could be used instead.

\subsection{Estimating the Environmentally Responsible Happy Nation Index}

The Environmentally Responsible Happy Nation Index (ERHNI) may be estimated for the various nations in the world if sufficient data are available. If we wait until we have perfect data, we will wait forever. Partly for the purpose of illustration and partly to kick start the endeavour, I calculated the ERHNI indices for 142 countries with available data (in 2006) based on very rough estimates of the relevant variables in $\mathrm{Ng}$ (2008), which should be consulted on the detailed method of estimation. Here only some of the results are reported.

The results show that nations with low ERHNI indices are mainly African and former communist countries (with their poverty and difficulties of transition, respectively), ${ }^{3}$ due more to their low life satisfaction figures than their high external costs. In Asia, only Pakistan has a negative figure and no nation in Western Europe and (North and Latin) Americas has a negative index. This is partly because our estimate of PCEC is conservative or has a significantly downward bias. However, although our conservative estimate of external costs does not turn the ERHNI of these nations into a negative figure, it nevertheless gives a different picture than just the figures for HLY. For example, in North America, Canada and the USA have very similar values in terms of life satisfaction, but Canada has an ERHNI value (11.3) significantly higher that of the USA (8.064) due to a lower per capita total CO2 emission (and hence our estimate of PCEC) of Canada than USA. Nations in Western Europe which mostly have emission figures even lower than Canada, register high ERHNI figures, taking six out of the top ten nations reported in Table 8.1, with Switzerland and Denmark heading the list. Leading nations in the Asia-Pacific area are New

\footnotetext{
${ }^{3}$ On the negative effects of transition on happiness, especially for Poland and Russia, see Brzezinski (2019).
} 
Table 8.1 Top scores in ERHNI, 2008 estimates

\begin{tabular}{l|l|c}
\hline & Country & ERHNI \\
\hline & WORLD & $\mathbf{4 . 7 0 5}$ \\
\hline 1 & Weighted Average & 22.789 \\
\hline 2 & Switzerland & 19.339 \\
\hline 3 & Denmark & 18.745 \\
\hline 4 & Costa Rica & 18.534 \\
\hline 5 & Sweden & 17.536 \\
\hline 6 & Austria & 15.430 \\
\hline 8 & Panama & 15.261 \\
\hline 9 & Colombia & 14.963 \\
\hline 10 & Netherlands & 14.716 \\
\hline & Ireland & 14.533 \\
\hline & ASIA-PACIFIC & \\
\hline 1 & Average & $\mathbf{5 . 1 5 8}$ \\
\hline 3 & New Zealand & 14.304 \\
\hline 4 & Malaysia & 14.167 \\
\hline 5 & Indonesia & 9.967 \\
\hline & Philippines & 9.346 \\
\hline & Mongolia & 9.240 \\
\hline
\end{tabular}

Zealand, Malaysia, Indonesia, Philippines, and Mongolia, as listed in the lower part of Table 8.1. A table reporting the results for all the 142 countries is in $\mathrm{Ng}$ (2008). (This has been extended and updated by Chen et al. (2016) the result of which is reported in Table 8.2.)

Following $\mathrm{Ng}$ (2008), Chen et al. (2016) make some important refinements to the proposed ERHNI and use wider (than just CO2) scope for external costs and also using more updated (2015) data and have a new estimate for an expanded set of 151 countries. Only the top 15 scorers are reported in Table 8.2.

\subsection{Concluding Remarks}

It is true that the existing happiness or life satisfaction measures are not perfectly accurate and the external costs measures are also very rudimentary and incomplete. However, we did not wait for the measure of GNP to be improved by the green adjustments, the PPP adjustments, etc. before using it. We also did not wait for the measures of happiness and life satisfaction to be perfected before using them. Recent happiness studies show that income is a poor correlate with happiness (Chap. 7), especially at the social level. Our ultimate objective is really happiness rather than 

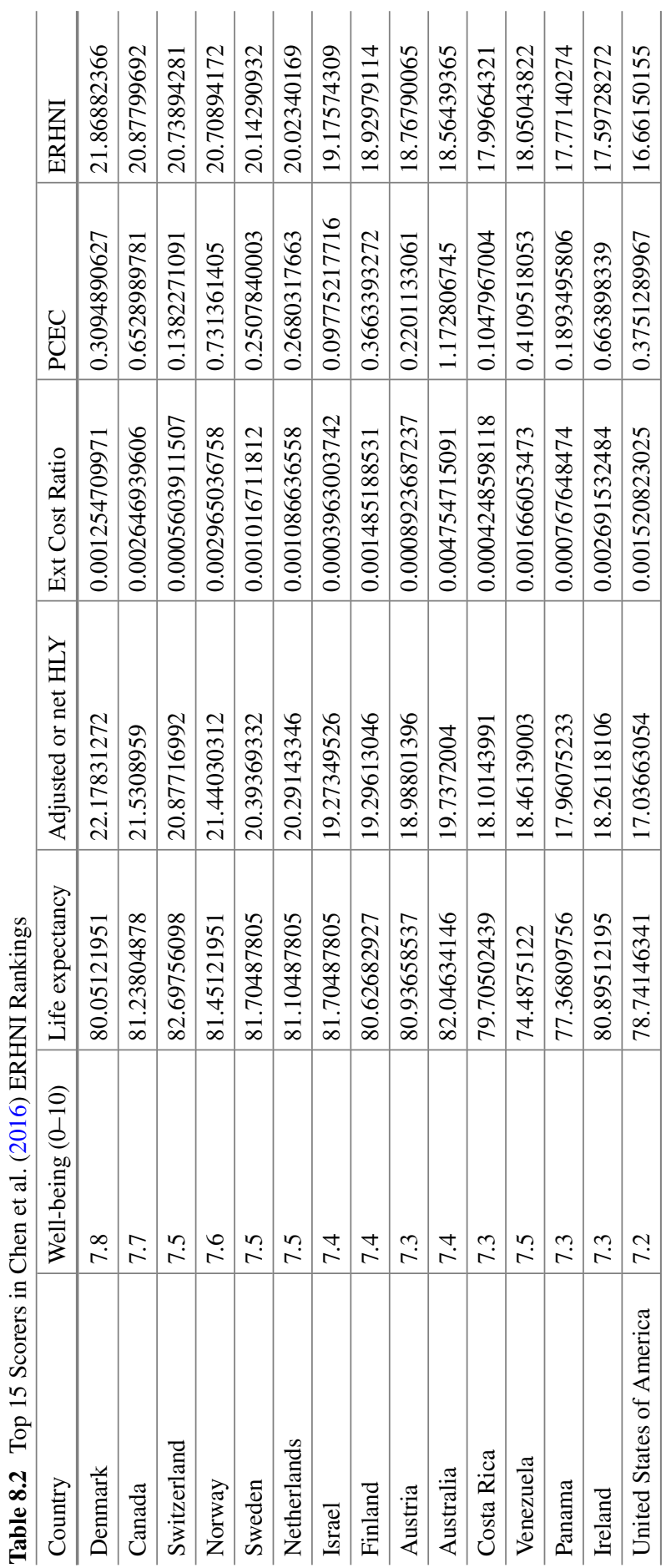
incomes. Thus, having a measure of national success in terms of some appropriate measure of happiness is very important. Moreover, just shifting to happiness alone is not sufficient. If each of the 200 or so nations in the world strives to increase the happiness level of its own people without sufficient check on the external costs imposed on the rest of the world, we may still have the tragedy of the commons.

A desirable national success indicator should take into account not only the (average) happy live years achieved for its own people, but must also take into (negative) account the external costs (only global environmental disruption is taken into account in this chapter, but the concept could be extended) imposed on others (including the future). The Environmentally Responsible Happy Nation Index (ERHNI) is proposed to serve this purpose. The calculation of this for the various nations reported in the last section is based on very rough and incomplete estimates. Nevertheless, it is hoped that, with further improvements, it will lead to some reorientation of both the market and national governments towards something more fundamentally valuable and less damaging to our life support system.

\section{References}

AHUVIA, Aaron. (2008). If money doesn't make us happy, why do we act as if it does? Journal of Economic Psychology, 29, 491-507.

ANDREWS, Frank M. \& WITHEY, Stephen B. (1976). Social Indicators of Well-Being: American's Perceptions of Life Quality. Plenum Press.

ASADULLAH, M. N., XIAO, S., \& YEOH, E. (2018). Subjective well-being in China, 2005-2010: The role of relative income, gender, and location. China Economic Review, 48, 83-101.

BRZEZINSKI, M. (2019). Diagnosing Unhappiness Dynamics: Evidence from Poland and Russia. Journal of Happiness Studies, 20, 2291-2327. https://doi.org/10.1007/s10902-018-0044-6

CAMPBELL, Angus, CONVERSE, Philip. E. \& RODGERS, Willard L. (1976). The Quality of American Life: Perceptions, Evaluations, and Satisfactions. Russell Sage Foundation.

CHEN, Enjiao, NG, Yew-Kwang, TAN, Yu Fen, TOH, Jesselyn Shi Ying. (2016). Environmentally responsible happy nation index: Refinements and 2015 rankings. Social Indicators Research. https://doi.org/10.1007/s11205-016-1422-2

CHENG, H., CHEN, C., LI, D., \& YU, H. (2018). The mystery of Chinese people's happiness. Journal of Happiness Studies, 19(7), 2095-2114.

CUMMINS, Robert A., ECKERSLEY, Richard, PALLANT, Julie, VAN VUGT, Jackie \& MISAJON, Rose Anne. (2003). Developing a national index of subjective wellbeing: The Australian Unity Wellbeing Index. Social Indicators Research, 64, 159-190.

DIENER, Ed (2000). Subjective well-being: the science of happiness and a proposal for a national index. American Psychologist, 55: 34-43.

DI TELLA, Rafael \& MACCULLOCH, Robert (2006). Some uses of happiness data in economics. Journal of Economic Perspectives, 20(1), 25-46.

FREY, Bruno S. \& STUTZER, Alois. (2002). Happiness and Economics: How the Economy and Institutions Affect Well-Being. Princeton University Press.

HAGERTY, Michael R., CUMMINS, Robert A., FERRISS, Abbott L., LAND, Kenneth, MICHALOS, Alex C., PETERSON, Mark, SHARPE, Andrew, SIRGY, Joseph \& VOGEL, Joachim. (2001). Quality of Life Indexes for National Policy: Review and Agenda for Research. Social Indicators Research, 55(1), 1-96.

HAJIRAN, Homayoun. (2006). Toward a quality of life theory: Net domestic product of happiness. Social Indicators Research, 75(1), 31-43. 
HALSTEAD, T. (1998). The science and politics of new measures of progress: A United States perspective. In R. Eckersley (Ed.), Measuring Progress: Is Life Getting Better? (pp. 53-68). CSIRO Publishing.

HAMILTON, C. (1998). Measuring changes in economic welfare: The genuine progress indicator for Australia. In R. Eckersley (Ed.), Measuring Progress: Is Life Getting Better? (pp. 69-92). CSIRO Publishing.

JACKSON, Tim. (2004). Chasing Progress: Beyond Measuring Economic Growth. New Economic Foundation.

KAHNEMAN, Daniel \& KRUEGER, Alan B. (2006). Developments in the measurement of subjective well-being. Journal of Economic Perspectives, 20(1), 3-24.

KAHNEMAN, Daniel, KRUEGER, Alan B., SCHKADE, David, SCHWARTZ, Norbert \& STONE, Arthur. (2004). Toward national well-being accounts. American Economic Review, 94(2), 429434.

LAYARD, Richard. (2005). Happiness: Lessons from a New Science. Penguin.

LUO, Yangmei, WANG, Tong, and HUANG, Xiting. (2018). Which types of income matter most for well-being in China: Absolute, relative or income aspirations? International Journal of Psychology, 53(3), 218-222.

MARKS, Nic, et al. (2006), The Happy Planet Index. London: New Economics Foundation. Available at http://www.happyplanetindex.org

NG, Yew-Kwang. (1975). Bentham or Bergson? Finite sensibility, utility functions, and social welfare functions. Review of Economic Studies, 42, 545-570.

NG, Yew-Kwang. (1984). Expected subjective utility: Is the Neumann-Morgenstern utility the same as the neoclassical's? Social Choice and Welfare, 1(3), 177-186.

NG, Yew-Kwang. (2000). Efficiency, Equality, and Public Policy: With a Case for Higher Public Spending. Macmillan.

NG, Yew-Kwang. (2008). Environmentally responsible happy nation index. Social Indicators Research, 85, 425-446.

OTT, Jan. (2005). Level and inequality of happiness in nations: Does greater happiness of a greater number imply greater inequality in happiness? Journal of Happiness Studies, 6(4), 397-420.

RIDZI, Frank, STEVENS, Chantal \& DAVERN, Melanie (2020). Community Quality-of-Life Indicators, Springer.

RUGGERI, K., GARCIA-GARZON, E., MAGUIRE, Á. et al. (2020). Well-being is more than happiness and life satisfaction: A multidimensional analysis of 21 countries. Health and Quality of Life Outcomes, 18, 192. https://doi.org/10.1186/s12955-020-01423-y

SHERMAN, A., SHAVIT, T. \& BAROKAS, G. (2020). A dynamic model on happiness and exogenous wealth shock: The case of lottery winners. Journal of Happiness Studies, 21(1), 117-137. https://doi.org/10.1007/s10902-019-00079-w

TANAKA, S. and TOKIMATSU, K. (2020). Social capital, subjective well-being, and happiness: Evidence from a survey in various European and Asian countries to address the Stiglitz report. Modern Economy, 11, 322-348. https://doi.org/10.4236/me.2020.112026

VAN PRAAG, Bernard \& FERRER-I-CARBONELL, Ada (2004).Happiness Quantified: A Satisfaction Calculus Approach. Oxford University Press.

VEENHOVEN, Ruut. (1996). Happy life-expectancy: A comprehensive measure of quality-of-life in Nations. Social Indicators Research, 39, 1-58. 
Open Access This chapter is licensed under the terms of the Creative Commons Attribution 4.0 International License (http://creativecommons.org/licenses/by/4.0/), which permits use, sharing, adaptation, distribution and reproduction in any medium or format, as long as you give appropriate credit to the original author(s) and the source, provide a link to the Creative Commons license and indicate if changes were made.

The images or other third party material in this chapter are included in the chapter's Creative Commons license, unless indicated otherwise in a credit line to the material. If material is not included in the chapter's Creative Commons license and your intended use is not permitted by statutory regulation or exceeds the permitted use, you will need to obtain permission directly from the copyright holder.

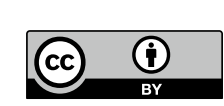

